\title{
KOMUNITAS
}

Jurnal Pengembangan Masyarakat Islam

Vol. 10, No. 2, Desember 2019

\section{KELOMPOK WANITA TANI (KWT) PELANGI KOPI SEBAGAI INOVASI PEMBERDAYAAN JANDA GUNA MENGENTASKAN KEMISKINAN DI DESA GIRI MULYO}

\author{
Doli Witro \\ Fakultas Syari'ah, Institut Agama Islam Negeri (IAIN) Kerinci \\ Email: doliwitro01@gmail.com
}

\begin{abstract}
This paper intends to explore further about the widow empowerment activities carried out by the Women Farmers Group (KWT) located in Giri Mulyo Village, Kayu Aro Barat District, Kerinci Regency. As it is known, KWT Pelangi Kopi aims to improve the lives of the people of Giri Mulyo Village by prioritizing women who are widows. KWT Pelangi Kopi focuses its activities on local agricultural products, such as coffee, oranges, and turquoise eggplants. Agricultural products are processed into various products to sell, so that it can increase the income of the members. This community is important and interesting to study, because the activities / programs they run are closely related to the poverty alleviation agenda and improving people's welfare which is an important agenda of the government, even in all countries in the world. This community has become even more interesting because its members are only women and are also managed by women. Thus, besides being related to poverty and welfare issues, this community is also closely related to women's empowerment.
\end{abstract}

Keywords: KWT Pelangi Kopi, Empowerment of Widows, Poverty

\section{A. Pendahuluan}

Badan Perencanaan Pembangunan Nasional (Bappenas) menyatakan bahwa dalam enam tahun terakhir, angka kemiskinan di Indonesia terus menurun. ${ }^{1}$ Namun demikian, Yayasan Pemberdayaan Perempuan Kepala Keluarga (Pekka) merilis laporan bahwa rumah tangga miskin yang dikepalai perempuan justru meningkat. ${ }^{2}$ Problem meningkatnya Rumah Tangga Miskin yang Dikepalai Perempuan (RTM-P) tampaknya juga menjadi perhatian serius pemerintah dengan masuknya isu ini ke dalam dokumen Rencana Pembangunan Jangka Menengah Nasional (RPJMN) 2015-2019. ${ }^{3}$

Meningkatnya angka perempuan kepala keluarga selaras dengan peningkatan angka perceraian di Indonesia dari tahun ke tahun. Menteri Agama

1 Badan Pusat Statistik (BPS) merilis bahwa angka kemiskinan di Indonesia pada September 2017 berada pada 10,12 persen atau 26,58 juta dari seluruh penduduk Indonesia, lalu pada September 2018 turun menjadi 9,66 persen atau sama dengan 25,67 juta dari total penduduk Indonesia. https://www.bps.go.id/, diakses pada 1 April 2019.

2 Yayasan Program Pemberdayaan Perempuan Kepala Keluarga (Pekka), Laporan Tahun 2017. Jakarta: 2017, h. 2.

3 Lampiran Peraturan Presiden Republik Indonesia Nomor 2 Tahun 2015 Tentang Rencana Pembangunan Jangka Menengah Nasional (RPJMN) 2015-2019,y Bab 1, sub poin 1.1.3, h. 1-15.

Komunitas: Jurnal Pengembangan Masyarakat Islam 
RI, Lukman Hakim Saifuddin, menyatakan bahwa berdasarkan data di Kementerian Agama (Kemenag), angka perceraian pada 2015 mencapai 398.245, lalu pada 2017 meningkat menjadi 415.898. ${ }^{4}$ Angka ini belum termasuk perempuan yang ditinggal mati suami (cerai mati). Asumsi yang terbangun berangkat dari data tersebut, setiap kali terjadi perceraian, biasanya perempuan akan menjadi kepala di keluarganya, karena suaminya sudah tidak ada.

Perceraian berimplikasi pada munculnya peran baru perempuan dalam keluarga. Selain menjadi kepala keluarga dan mengurus anak-anak, perempuan kepala keluarga juga akan berperan penuh dalam urusan nafkah keluarganya. Kondisi ini rentan terhadap perekonomian keluarga yang semakin memburuk. Tidak jarang di antara mereka masuk ke dalam jerat rentenir. ${ }^{5}$ Tim Nasional Percepatan dan Penanggulangan Kemiskinan (TNP2K), sebagaimana dikutip dalam Laporan Yayasan Pekka tahun 2017, juga mencatat bahwa tingkat kedalaman dan keparahan kemiskinan RTM-P lebih buruh ketimbang RTM-L. Penurunan tingkat kedalaman kemiskinan RTM-P hanya 19 persen, sementara RTM-L mencapai 25 persen. $^{6}$

Tren angka kemiskinan ini menyebar di hampir seluruh wilayah Indonesia, salah satunya Kabupaten Kerinci, Provinsi Jambi. Pada 2017, terdapat 17.621 orang penduduk miskin di Kabupaten Kerinci, lalu pada 2018 turun sebanyak 4,7 persen atau sama dengan 831 orang sehingga menjadi 16.790 orang. ${ }^{7}$ Seiring itu, terjadi juga peningkatan angka RTM-P seiring tingginya angka perceraian di Kabupaten Kerinci. Panitera Pengadilan Agama Kerinci, Auza'i, pada 27 September 2018 menyatakan bahwa angkat Perceraian di Kabupaten Kerinci dan Sungai Penuh pada 2017 mencapai 274 perkara, lalu pada 2018 meningkat menjadi 262 perkara. $^{8}$

4 Menteri Agama: Angka Perceraian di Indonesia Meningkat, berita pada https://kumparan.com/2018/12/07, diakses pada 10 April 2019

${ }^{5}$ Margaretta Erna Setianingrum dan Ratriana Yuliastuti Endang Kusumiati, "Quality of Life Janda Lanjut Usia yang Tinggal di Pedesaan", Prosiding Temui Ilmiah X Ikatan Psikologi Perkembangan Indonesia, Semarang: 22-24 Agustus 2017, h. 215.

6 Yayasan Pekka, op. cit, h.3

7 Kerincitime.co.id, Angka Kemiskinan di Kerinci Turun 4,7 Persen, (Online), (https://kerincitime.co.id/, diakses pada 10 April 2019).

${ }^{8}$ Angka Perceraian di Kerinci dan Sungai Penuh Meningkat, ini Faktor Penyebabnya, berita pada https://jambi.tribunnews.com/2018/09/27, diakses pada 10 April 2018 
Doli Witro

Dari segi potensi perekonomian lokal, Kabupaten Kerinci dikenal sebagai daerah yang subur dan memiliki hasil pertanian yang bagus. Ketika diadakan Festival Kopi di Jakarta pada 2017, kopi asal Kabupaten Kerinci meraih predikat "Kopi Terbaik se-Indonesia". ${ }^{9}$ Kopi tersebut berjenis kopi arabika. Kopi ini terdapat setidaknya di tiga kecamatan, yaitu Kecamatan Kayu Aro, Kecamatan Kayu Aro Barat, dan Kecamatan Gunung Tujuh seluas. Selain kopi, daerah Kerinci juga menghasilkan teh, jeruk, terong pirus, dan lain sebagainya.

Dengan potensi perekonomian yang besar itu, seharusnya kemiskinan bukan lagi menjadi kondisi yang perlu dikhawatirkan oleh setiap kepala keluarga, walaupun keluarga itu dikepalai oleh seorang perempuan. Berangkat dari pandangan ini, seorang aktivis sosial, Erna Yunita, membangun sebuah komunitas beranggotakan wanita. Anggota komunitas ini terdiri dari wanitawanita kepala yang berperan sebagai tulang punggung keluarga. Komunitas ini bernama Kelompok Wanita Tani (KWT), berlokasi di Desa Giri Mulyo, Kecamatan Kayu Aro Barat, Kabupaten Kerinci. Erna menyatakan:

Ada 20-an orang wanita yang menjadi anggota KWT Pelangi Kopi. Beberapa di antara mereka berstatus janda. KWT Pelangi Kopi bertujuan untuk menyejahterakan kehidupan masyarakat Desa Giri Mulyo dengan mengutamakan perempuan yang berstatus sebagai janda. KWT Pelangi Kopi memfokuskan kegiatannya pada hasil pertanian lokal, seperti kopi, jeruk, dan terong pirus. Hasil pertanian ini diolah menjadi berbagai produk untuk dijual, sehingga dapat meningkatkan penghasilan para anggota. ${ }^{10}$

Berdasarkan uraian di atas, penulis bermaksud menelaah lebih lanjut tentang kegiatan pemberdayaan janda yang dilakukan oleh KWT Pelangi Kopi tersebut. Komunitas ini menjadi penting dan menarik ditelaah, karena kegiatan mereka terkait erat dengan agenda pengentasan kemiskinan dan peningkatan kesejahteraan masyarakat yang merupakan agenda penting pemerintah, bahkan di seluruh negara di dunia. Komunitas ini menjadi semakin menarik karena anggotanya hanya perempuan dan dikelola juga oleh perempuan. Dengan demikian, selain terkait dengan isu kemiskinan dan kesejahteraan, komunitas ini juga erat dengan pemberdayaan perempuan.

9 Harian Nasional, Mengenal Kopi Kerinci, Kopi Terbaik se-Indonesia, (Online), (http://harnas.co/, diakses pada 10 April 2019).

10 Erna Yunita, Ketua KWT Pelangi Kopi, Wawancara, Giri Mulyo, 19 April 2019.

Komunitas: Jurnal Pengembangan Masyarakat Islam 


\section{B. METODOLOGI PENELITIAN}

Berdasarkan objek, penelitian ini adalah penelitian lapangan (field research). Penyajian data dilakukan secara naratif deskriptif. Pada penulisan hasil penelitian, penulis menitikberatkan penalaran yang berdasarkan realitas sosial secara obyektif dan melalui paradigma fenomenologis. Paradigma fenomenologis, artinya memahami arti peristiwa dan kaitannya dalam situasi tertentu. ${ }^{11}$

Penulisan dengan paradigma fenomenologis ini digunakan atas tiga pertimbangan. Pertama, untuk mempermudah pemahaman realitas ganda. Kedua, menyajikan secara hakiki antara penelitian dan realitas. Ketiga, metode ini lebih peka dan menyesuikan diri pada bentuk nilai yang dihadapi. Oleh karenanya, penulisan ini bukan hanya penulisan kepustakaan dan bukan pula kegiatan penulisan hasil penelitian lapangan saja, tetapi merupakan gabungan antara keduanya.

Dalam studi penulisan karya tulis ilmiah ini, telaah pustaka dilakukan sejak awal ketika hendak menentukan topik yang akan menjadi fokus kajian dan ketika hendak melakukan analisis terhadap data yang diperoleh dari lapangan. Kegiatan ini juga dilakukan untuk memperoleh data yang bersumber dari kepustakaan. Sedangkan penulisan penelitian lapangan diawali dengan kegiatan penjajakan, untuk mengetahui relevansi antara obyek yang hendak diteliti dengan permasalahan studi ini. Oleh karenanya, penulisan ini menggunakan pendekatan penelitian studi kasus (case study).

Dalam studi kasus ini, penulis mengadakan telaah secara mendalam tentang pemberdayaan janda yang dilakukan oleh KWT Pelangi Kopi. Dalam studi kasus ini, "kesimpulan hanya berlaku atau terbatas pada kasus tertentu saja". ${ }^{12}$ Studi kasus yang penulis gunakan dikarenakan untuk mengetahui pemberdayaan janda oleh KWT Pelangi Kopi di Desa Giri Mulyo.

Penelitian karya tulis ilmiah ini dilaksanakan di Desa Giri Mulyo Kecamatan Kayu Aro Barat, Kabupaten Kerinci dan lebih berpusat pada KWT Pelangi Kopi dalam pemberdayaan janda. Penelitian ini dilakukan sejak bulan

11 Pujiono Pranoto, Kamus Research, (Bandung: Angkasa, 1984), h. 120. Lihat juga, Sartono Kartodirjo, Pendekatan IImu Sosial dalam Metodologi Sejarah, (Jakarta: PT. Gramedia Pustaka Utama, 1992), h. 87.

12 Iskandar, Metodologi Penelitian Pendidikan dan Sosial (Kuantitatif dan Kualitatif), (Jakarta: Gaung Persada, 2009), Cet. Ke-2, h. 207. 
Doli Witro

Maret sampai dengan bulan Mei 2019. Waktu penulisan itu dapat saja berubah jika hasil penelitian yang didapat belum valid.

Adapun data yang digunakan dalam penelitian ini adalah: Pertama, data primer, yaitu data yang diperoleh langsung dari sumbernya. ${ }^{13}$ Data primer ini diperoleh langsung dari responden dan informan. Responden yaitu orang terlibat langsung pada pemberdayaan janda dalam KWT Pelangi Kopi, antara lain: 1) Ketua KWT Pelangi Kopi; dan 2) Anggota KWT Pelangi Kopi. Selanjutnya, Informan yaitu orang yang tidak terlibat langsung pada pemberdayaan janda dalam KWT Pelangi Kopi, antara lain: 1) Kepala Desa Giri Mulyo; 2) Ketua Badan Permusyawaratan Desa ${ }^{14}$ (BPD) Desa Giri Mulyo; dan 3) Masyarakat Desa Giri Mulyo. Kedua, data sekunder yaitu mencakup dokumen-dokumen resmi, buku-buku, hasil-hasil penelitian yang berwujud laporan, dan sebagainya yang berkaitan dengan KWT Pelangi Kopi. ${ }^{15}$

Metode pengumpulan data yang digunakan adalah observasi, wawancara, dan dokumentasi. Metode observasi penulis gunakan untuk melihat secara langsung ke lapangan guna mengadakan pengamatan terhadap orang-orang yang telah ditentukan sebagai responden dan mencatat data yang diperlukan. Metode ini digunakan untuk mengamati responden secara dekat, yang selanjutnya ditulis dalam lembar observasi. Observasi ini bertujuan untuk mengetahui pemberdayaan janda oleh KWT Pelangi Kopi di Desa Giri Mulyo.

Metode wawancara penulis gunakan untuk mengambil data tentang pandangan ketua dan anggota; KWT Pelangi Kopi, Kepala Desa dan Ketua BPD Desa Giri Mulyo dan masyarakat Giri Mulyo terhadap pemberdayaan janda yang dilakukan oleh KWT Pelangi Kopi. Data yang diperoleh dari wawancara digunakan untuk mendukung data-data yang penulis dapatkan dengan cara observasi dan dokumentasi.

Metode dokumentasi penulis gunakan untuk melengkapi hasil penelitian dengan cara mencari data-data yang berhubungan dengan sifat benda seperti data tentang letak geografis, nama-nama responden, nama-nama sumber data lapangan dan lain sebagainya. Metode ini digunakan juga untuk mengetahui

13 Amirudin dan Zainal Asikin, Pengantar Metode Penelitian Hukum, (Jakarta: PT RajaGrafindo Persada, 2012), h. 30.

${ }^{14}$ Selanjutnya Kalimat Badan Permusyawaratan Desa disebut dengan kata BPD saja.

${ }^{15}$ Amirudin dan Zainal Asikin, Pengantar Metode Penelitian ..., h. 30. 
struktur KWT Pelangi Kopi, profil pengusaha dan usaha kecil selai pelangi, sejarah berdirinya KWT Pelangi Kopi, dan lain sebagainya yang terkait dengan KWT Pelangi Kopi.

Teknik analisis data yang digunakan dalam penelitian ini ada beberapa teknik yaitu teknik analisis domain, teknik analisis taksonomi, dan teknik analisis komponensial. Teknik analisis domain biasanya digunakan untuk memperoleh gambaran atau pengertian yang bersifat umum dan relatif menyeluruh tentang apa yang mencakup dalam suatu fokus pokok permasalahan yang tengah diteliti. Analisis ini digunakan untuk memperoleh gambaran umum KWT Pelangi Kopi, untuk menganalisis pola yang digunakan KWT Pelangi Kopi dalam melakukan pemberdayaan janda seperti pendekatan, sosialisasi, nilai-nilai yang ditanamkan kepada anggota serta strategi yang digunakan untuk merekrut anggota KWT Pelangi Kopi.

Teknik analisis taksonomi adalah teknik analisis yang lebih rinci dan mendalam. Pada analisis ini fokus penelitian ditetapkan pada domain tertentu yang sangat berguna dalam upaya mendeskripsikan atau menjelaskan fenomena atau fokus yang menjadi sasaran penelitian. Analisis ini digunakan untuk menganalisis data secara lebih terperinci dan lebih mendalam tentang pemberdayaan janda yang dilakukan KWT Pelangi Kopi dalam pengentasan kemiskinan di Desa Giri Mulyo.

Teknik analisis komponensial adalah teknik analisis yang dilakukan setelah penulis mempunyai cukup banyak fakta atau informasi dari hasil observasi dan wawancara yang melacak kontras-kontras di antara warga domain. Analisis ini penulis gunakan untuk menganalisis data implikasi sosial dan ekonomi pemberdayaan janda terhadap anggota KWT Pelangi Kopi secara mendalam. Data itu dianalisis guna mengetahui upaya-upaya untuk menjaga pemberdayaan janda di Giri Mulyo agar tetap berkelanjutan.

\section{HASIL DAN PEMBAHASAN}

\section{Pola Pemberdayaan Janda KWT Pelangi Kopi}

Adapun yang dimaksud dengan pola adalah pendekatan yang dilakukan terhadap anggota KWT Pelangi Kopi, nilai-nilai yang ditanam kepada anggota 
Doli Witro

KWT Pelangi Kopi, sosialisasi dalam merekrut anggota KWT Pelangi Kopi, dan strategi pemberdayaan janda oleh KWT Pelangi Kopi.

a. Pendekatan

Pendekatan merupakan cara untuk mendekati sesuatu sehingga output dari hal tersebut menghasilkan sikap atau pandangan tentang sesuatu; yang berupa pemikiran atau seperangkat pemikiran yang saling berkaitan. Pendekatan sangat perlukan dalam membentuk suatu kelompok. Dengan pendekatan visi dan misi antar anggota dalam suatu kelompok bisa disatukan.

Pada KWT Pelangi Kopi pendekatan yang digunakan oleh pendiri komunitas tersebut adalah pendekatan profesi. Hal ini berangkat dari masyarakat yang direkrut menjadi anggota KWT Pelangi Kopi. Setiap masyarakat yang direkrut rata-rata mempunyai kebun kopi; ada sebagian masyarakat yang tidak memiliki kebun kopi, tetapi ia bisa menanam, memelihara dan memetik tanaman. Sehingga semua anggota KWT Pelangi kopi merupakan petani yang saling melengkapi satu sama lain.

Erna Yunita menyatakan:

KWT Pelangi Kopi dibentuk atas dasar anggota sama-sama petani kopi. Hal ini juga yang membuat hubungan antar anggota KWT Pelangi Kopi sampai saat ini masih kompak. Karena setiap anggota memiliki tujuan yang sama yaitu mengegola kopi. Selain itu KWT Pelangi Kopi ketika dibentuk bersamaan dengan adanya program Millenium Challenge Account Indonesia (MCAl) dalam meningkatkan kapasitas petani kopi daerah Kerinci untuk meminimalisir perambahan hutan. ${ }^{16}$

b. Nilai-nilai yang ditanam

KWT Pelangi Kopi dalam pelaksanaan program-program kerja mengutamakan nilai kreativitas. Hal ini tercermin ketika kopi sudah berhasil ditanam, diracik hingga siap untuk dijual dalam satu terakhir. Para anggota KWT Pelangi Kopi menghadirkan program-program terbaru sepeti membuat "Selai Jeruk Marmalade, Selai Terong Pirus, Selai Raspberry, Selai Strawberry, Selai Bawang Dayak, dan Selai Nanas". ${ }^{17}$

\footnotetext{
${ }^{16}$ Erna Yunita, Ketua KWT Pelangi Kopi, Wawancara, Giri Mulyo, 19 April 2019.

${ }^{17}$ Suwarni, Anggota KWT Pelangi Kopi (berstatus janda), Wawancara, Giri Mulyo, 1 Mei 2019.
}

Komunitas: Jurnal Pengembangan Masyarakat Islam 
Nilai kebersamaan juga tidak luput diterapkan dalam KWT Pelangi Kopi. Nilai tersebut terlihat ketika para anggota KWT Pelangi Kopi mengadakan arisan dua minggu satu kali, biasanya bertempat di rumah Erna Yunita -Ketua KWT Pelangi Kopi. Di sinilah para anggota KWT Pelangi Kopi berbagi pengamalan mulai dari menanam, memelihara dan memananen kopi.

c. Sosialisasi

KWT Pelangi Kopi dibentuk pada tahun 2017 yang bermula pada kesadaran para anggotanya akan potensi yang besar dalam hal komoditi kopi. ${ }^{18} \mathrm{Hal}$ ini didukung faktor letak geografis Kabupaten Kerinci khususnya Kecamatan Kayu Aro Barat yang berada di wilayah dataran tinggi yang mencapai 1700 Mdpl dengan tanah vulkanik dari Gunung Kerinci (3805 Mdpl) yang sangat cocok bagi syarat hidup tanaman kopi arabika yang berkualitas premium. ${ }^{19}$

Dalam pembentukannya menjadi sebuah perkumpulan yang legal dan berbadan hukum, komunitas ini bersama-sama dengam komunitas Alam Korintji ${ }^{20}$ (Alko) - sebuah komunitas yang terdiri dari 14 kelompok tani, dua di antaranya adalah kelompok wanita tani, salah satunya KWT Pelangi Kopi. ${ }^{21}$

Selain dibantu Millenium Challenge Account Indonesia (MCAI) komunitas Alam Korintji (Alco) dibantu juga oleh Non Government Organization (NGO), World Wide Fund (WWF), dan Lembaga Advokasi Hak Rakyat (Lahar). Seiring berjalannya kegiatan-kegiatan yang diadakan komunitas Alko, KWT Pelangi Kopi secara tidak langsung dikenal banyak orang.

d. Strategi Pemberdayaan Janda

Pada awalnya kegiatan KWT Pelangi Kopi terbatas hanya pada pelatihan, pendidikan dan sosialisasi bagi anggota dan penyebarluasan pengetahuan cara bertani kopi. Mulai dari teknik penanaman, perawatan sampai teknik pemaneman sehingga menghasilkan buah kopi atau red cerry yang berkualitas dan berkelanjutan. Kemudian dengan adanya bantuan

\footnotetext{
18 Dedi Haryanto, Kepala Desa Giri Mulyo, Wawancara, Giri Mulyo, 1 Mei 2019.

19 Juli, Ketua BPD Desa Giri Mulyo, Wawancara, Giri Mulyo, 1 Mei 2019.

20 Selanjutnya Kalimat Alam Korintji disebut dengan kata Alko saja.

21 Erna Yunita, Ketua KWT Pelangi Kopi, Wawancara, Giri Mulyo, 19 April 2019.
} 
Doli Witro

berupa mini factory atau pabrik kecil sebagai model industri yang dimiliki secara bersama-sama 14 kelompok tani lainnya, memungkinkan KWT Pelangi Kopi belajar lebih lanjut lagi mengenai processing pascapanen tanaman kopi sehingga bisa meningkatkan nilai tambah.

Sesuai yang tertera dalam akta notaris, bahwa dalam perkembangannya kegiatan KWT Pelangi Kopi tidak terbatas hanya komoditas kopi saja. Tetapi telah dikembangkan potensi-potensi lain yang intinya berdampak positif terhadap peningkatan peran perempuan dalam meningkatkan perekonomian keluarga. ${ }^{22}$ Oleh karena itu, KWT Pelangi Kopi juga mencoba menggali potensi buah lokal dengan membuat produk olahan 5 varian selai buah lokal yaitu Selai Terong Pirus, Selai Jeruk Marmalade (Selai Jeruk dengan Kulit), Selai Strawberry, Selai Raspberry, Selai Bawang Dayak, dan Selai Nanas.

Dengan Brand Selai Pelangi yang menjual sisi keaslian buah tanpa pektin tambahan sehingga persentase buah lebih banyak dari persentase gula, dari bahan baku organik, tanpa zat kimia pengawet, kaya vitamin, dan menyehatkan serta tentunya dengan harga yang terjangkau. ${ }^{23}$

Selai kemasan botol (300 Gram) dijual dengan harga Rp. 32.000, meliputi varian Selai Terong Pirus, Selai Jeruk Marmalade, Dan Selai Nanas. Sementara selai varian Selai Raspberry dan Selai Strawberry dijual dengan harga Rp. 34.000. Target pemasaran selai KWT Pelangi Kopi untuk dijual di mini market, para pendaki gunung, konsumen umum, secara online, toko online Alko, pusat oleh-oleh, toko kue, hotel dan restoran untuk pendamping menu sarapan pagi. ${ }^{24}$

Adapun harga eceran untuk Kopi Arabika Kemasan (100 gram) dengan varian Full Wash Processed dijual dengan harga Rp. 35.000. Sementara varian Natural Processed dengan harga Rp. 37.000. Adapun harga eceran Kopi Arabika Kemasan (200 gram) dengan varian Full Wash Processed dijual dengan Rp. 70.000. Sementara varian Natural Processed dengan harga Rp. 74.000. Sedangkan untuk harga kemasan (satu kilogram) varian Full Wash Processed dijual dengan harga Rp 345.000. Sedangkan

\footnotetext{
22 Eva Marlina, Anggota KWT Pelangi Kopi, Wawancara, Giri Mulyo, 4 Mei 2019.

23 Efrina, Anggota KWT Pelangi Kopi, Wawancara, Giri Mulyo, 4 Mei 2019.

24 Erna Yunita, Profil Usaha Kelompok Wanita Tani (KWT) Pelangi Kopi, (Kerinci: tidak diterbitkan, 2018), h. 2-3.
} 
kemasan (satu kilogram) varian Natural Processed dengan harga Rp. 365.000. Target pemasaran produk Pelangi Coffee adalah pembelian online, toko online Alko, pusat oleh-oleh, homestay dan guest house, serta untuk kebutuhan cafe dan warung kopi. ${ }^{25}$

\section{Implikasi Sosial dan Ekonomi Pemberdayaan Janda}

1. Sosial

Menurut Atchley kehilangan pasangan, sebagai peristiwa hidup yang signifikan memiliki dampak yang kuat pada sosial dan personal terhadap penyesuaian, kesehatan dan kepuasan kehidupan seseorang. ${ }^{26}$ Ketika pasangan meninggal korban tidak hanya harus menyesuaikan diri dengan hilangnya menutup hubungan, tetapi juga untuk mengelola keputusan dan tanggung jawab sehari-hari yang dulunya dikelola bersama. Menjanda dapat dianggap sebagai posisi baru yang melibatkan perubahan besar dalam diri perempuan baik peran dalam tujuan keluarga ataupun dalam masyarakat.

2. Ekonomi

Pembangunan perekonomian yang dilakukan oleh suatu negara adalah salah satu upaya untuk meningkatkan taraf hidup penduduknya. Pada negara yang sedang berkembang umumnya berusaha untuk mengembangkan diri dari masyarakat yang sifatnya tradisional dimana dalam kondisi yang masih terbelakang menuju ke arah yang lebih baik dan maju. Kalau ini dikaitkan dengan masalah ekonomi maka hal ini ditujukan ke arah mendapatkan tingkat kesejahteraan dan ekonomi yang lebih baik. ${ }^{27}$ Salah satu indikator keberhasilan pembangunan perekonomian suatu negara atau pemerintah adalah berkurangnya jumlah penduduk miskin karena pada hakekatnya suatu pembangunan adalah untuk meningkatkan kesejahteraan masyarakat secara adil dan merata.

Tingginya tingkat kemiskinan menjadi indikator bahwa masyarakat belum berperan menjadi subjek dalam pembangunan. Menjadi subjek dalam pembangunan adalah memberikan hak-haknya untuk berpartisipasi dalam pembentukkan dan produksi nasional. Untuk sampai pada tujuan tersebut

25 Erna Yunita, Profil Usaha Kelompok..., h. 3.

${ }^{26}$ Mehta, et. all., "Effect of Widowhood on Repression-Sensitisation Tendency, Journal of the Indian Academi of Applied Psychology, Vol. 1, No. 3, 2006, h. 41.

27 Putriana, "Strategi Penanggulangan Kemiskinan melalui Pemberdayaan Usaha Mikro, Kecil dan Menengah (UMKM)", Vol. 15, No. 2, 2014, h. 117. 
Doli Witro

rakyat harus memiliki modal material dan mental. Hal ini yang menjadi inspirasi untuk perlunya pemberdayaan ekonomi rakyat yang kemudian berkembang untuk membangun sistem perekonomian bercorak ekonomi kerakyatan. ${ }^{28}$ KWT Pelangi Kopi merupakan komunitas yang berperan dalam pemberdayaan ekonomi rakyat. Komunitas ini mengutamakan pemberdayaan perempuan yang berstatus sebagai janda.

Surtini mengatakan KWT Pelangi Kopi menyediakan pekerjaan sebagai pemetik kopi yang diberikan upah sebesar Rp. 55.000 per hari dengan durasi kerja dari jam 7 pagi sampai 12 siang. ${ }^{29}$ Apabila para petani sanggup bekerja dalam seminggu 4 hari saja, maka dalam satu bulan dapat menghasilkan Rp. 880.000 per bulan. Jika diukur dengan berpatokan pada ukuran kemiskinan bank dunia yaitu sebesar Rp. 401.220 per kapita satu bulan atau sama dengan $\mathrm{Rp}$. 13.374 per hari, maka penghasilan para petani kopi sudah di atas garis kemiskinan.

Kepala Badan Pusat Statistik ${ }^{30}$ (BPS) Suhariyanto mengatakan:

Hitung-hitungannya bukan dengan membagi pendapatan $\mathrm{Rp}$. 401.220 per bulan menjadi Rp. 13.374 per hari. Ada faktor lain yang perlu diperhatikan, yakni jumlah anggota keluarga. Kalau dibagi 30 hari, saya rasa tidak relevan. Saya sarankan dikalikan anggota rumah tangga. Kan yang dibutuhkan per rumah tangga. Biasanya, keluarga miskin memiliki anak lebih banyak. BPS mendapat angka 4,5 rata-rata anggota keluarga. Jadi, pendapatan perkapita per bulan tersebut dikalikan dengan 4,5. Didapatkan hasil $\mathrm{Rp} 1,8$ juta. Nilai tersebut masih di bawah upah minimum sehingga termasuk dalam kategori miskin. ${ }^{31}$

Berdasarkan pernyataan di atas penghasilan yang diperoleh para petani belum dapat menutupi kebutuhan sehari-hari. Kalau mengandalkan hasil dari memetik kopi saja. Oleh karena itu, diperlukan penghasilan tambahan melalui kopi yang diracik dalam kemasan. "Endang Wahyuni mengatakan dalam satu bulan KWT Pelangi Kopi dapat memproduksi 150 bungkus Kopi Arabika kemasan 200 gram dan kemasan 100 gram varian Full Wash Processed dan Natural Processe". ${ }^{32}$

\footnotetext{
28 Putriana, "Strategi Penanggulangan Kemiskinan..., h. 118.

29 Surtini, Petani Kopi (berstatus janda), Wawancara, Giri Mulyo, 4 Mei 2019.

30 Selanjutnya Kalimat Badan Pusat Statistik disebut dengan kata BPS saja.

31 Kompas.com, Begini Hitung-hitungan Angka Kemiskinan di Indonesia Cara BPS, (Online), (https://ekonomi.kompas.com, diakses pada 3 Mei 2019).

32 Endang Wahyuni, Anggota KWT Pelangi Kopi, Wawancara, Giri Mulyo, 4 Mei 2019.
} 
Jika setiap anggota KWT Pelangi Kopi mendapat bagian $2 \mathrm{~kg}-$ minsalnya, varian Full Wash Processed- dari hasil produksi dalam satu bulan, kemudian dijual, maka akan diperoleh hasil sebanyak Rp. 690.000. Selain itu anggota KWT Pelangi Kopi bisa juga memperoleh penghasilan tambahan dari selai yang dibuat dari buah-buahan yang ditanam disela-sela kopi -Selai Jeruk Marmalade, Selai Terong Pirus, Selai Raspberry, Selai Strawberry, Selai Bawang Dayak, dan Selai Nanas.

Erni Marlina mengatakan dalam satu bulan KWT Pelangi Kopi dapat memproduksi 500 Botol selai buah kemasan 300 gram yang meliputi semua varian -Selai Jeruk Marmalade, Selai Terong Pirus, Selai Raspberry, Selai Strawberry, Selai Bawang Dayak, dan Selai Nanas. ${ }^{33}$ Jika setiap anggota KWT Pelangi Kopi mendapat bagian 30 botol -misalnya, varian Selai Jeruk Marmalade- dari hasil produksi dalam satu bulan, kemudian dijual, maka akan diperoleh hasil sebanyak Rp. 640.000. Apabila semua program KWT Pelangi Kopi dijalan dengan berkelanjutan, maka akan dapat menutupi kebutuhan sehari-hari petani kopi di Desa Giri Mulyo.

\section{PENUTUP}

\section{Kesimpulan}

KWT Pelangi Kopi merupakan komunitas yang beranggotakan petani kopi wanita dan dibentuk bermula dari kesadaran para anggotanya akan potensi yang besar dalam hal komoditi kopi di Desa Giri Mulyo. Komunitas ini mempunyai target untuk mengentaskan kemiskinan dengan pemberdayaan perempuan yang mengutamakan anggota dan masyarakat yang berstatus janda. KWT Petani Kopi menawarkan beberapa program yang saling berkaitan dan mendukung satu sama lain. Diantaranya, Kopi Arabika Kemasan dengan varian Full Wash Processed dan Natural Processed. Selain itu, KWT Pelangi Kopi juga menawarkan Selai Terong Pirus, Selai Jeruk Marmalade (Selai Jeruk dengan Kulit), Selai Strawberry, Selai Raspberry, Selai Bawang Dayak, dan Selai Nanas. Dengan adanya program tersebut diharapkan dapat membantu masyarakat Desa Giri Mulyo untuk mengentaskan kemiskinan.

\section{Saran}

${ }^{33}$ Erni Marlina, Anggota KWT Pelangi Kopi (berstatus janda), Giri Mulyo, 4 Mei 2019. 
Doli Witro

Kepekaan terhadap kebutuhan hidup janda harus ditingkatkan baik dari pemerintah maupun masyarakat. Terlebih lagi janda tersebut memiliki beberapa anak. Oleh sebab itu, jika janda tidak diperhatikan maka kemiskinan akan bisa turun-temurun terhadap anak yang ditinggalkan. Terlebih lagi bisa menjadi bencana bagi bangsa Indonesia. Selain itu pemerintah juga harus membantu dari segi dana maupun motivasi untuk KWT Pelangi Kopi agar dapat dengan mudah melakukan setiap kegiatan maupun pengembangan program kerja.

\section{DAFTAR PUSTAKA}

Amirudin, dan Zainal Asikin, 2012, Pengantar Metode Penelitian Hukum, Jakarta: PT RajaGrafindo Persada.

Badan Pusat Statistik, Persentase Penduduk Miskin Pada September 2018 Sebesar 9,66 Persen, (Online), (https://www.bps.go.id/, diakses pada 10 Februari 2019).

Harian Nasional, Mengenal Kopi Kerinci, Kopi Terbaik se-Indonesia, (Online), (http://harnas.co/, diakses pada 10 Februari 2019).

Iskandar, 2009, Metodologi Penelitian Pendidikan dan Sosial (Kuantitatif dan Kualitatif), Jakarta: Gaung Persada, Cet. Ke-2.

Kartodirjo, Sartono, 1992, Pendekatan IImu Sosial dalam Metodologi Sejarah, Jakarta: PT. Gramedia Pustaka Utama.

Kerincitime.co.id, Angka Kemiskinan di Kerinci Turun 4,7 Persen, (Online), (https://kerincitime.co.id/, diakses pada 10 Februari 2019).

Kompas.com, Begini Hitung-hitungan Angka Kemiskinan di Indonesia Cara BPS, (Online), (https://ekonomi.kompas.com, diakses pada 3 Mei 2019).

Lampiran Peraturan Presiden Republik Indonesia Nomor 2 Tahun 2015 Tentang

Rencana Pembangunan Jangka Menengah Nasional (RPJMN) 2015-2019.

Mehta, et. all., 2006, "Effect of Widowhood on Repression-Sensitisation Tendency, Journal of the Indian Academi of Applied Psychology, Vol. 1, No. 3.

Pranoto, Pujiono, 1984, Kamus Research, Bandung: Angkasa.

Program Pemberdayaan Perempuan Kepala Keluarga (Pekka), 2017, Laporan Tahunan 2017, Jakarta: t.p.

Putri, Oktaviani Nindya, ddk., 2015, "Pemberdayaan Perempuan Kepala Keluarga", Prosiding KS: Riset \& PKM, Vol. 2, No. 2 
Putriana, 2012, "Strategi Penanggulangan Kemiskinan melalui Pemberdayaan Usaha Mikro, Kecil dan Menengah (UMKM)", Vol. 15, No. 2.

Setianingrum, Margaretta Erna dan Ratriana Yuliastuti Endang Kusumiati, "Quality of Life Janda Lanjut Usia yang Tinggal di Pedesaan", Prosiding Temui IImiah X Ikatan Psikologi Perkembangan Indonesia, Semarang: 22-24 Agustus 2017.

Sugiono, 2009, Metode Penelitian Kuantitatif dan Kualitatif, Bandung: Alfabeta.

\section{Wawancara}

Dedi Haryanto, Kepala Desa Giri Mulyo, Wawancara, Giri Mulyo, 1 Mei 2019.

Efrina, Anggota KWT Pelangi Kopi, Wawancara, Giri Mulyo, 4 Mei 2019.

Endang Wahyuni, Anggota KWT Pelangi Kopi, Wawancara, Giri Mulyo, 4 Mei 2019.

Erna Yunita, Ketua KWT Pelangi Kopi, Wawancara, Giri Mulyo, 19 April 2019.

Erni Marlina, Anggota KWT Pelangi Kopi (berstatus janda), Giri Mulyo, 4 Mei 2019.

Eva Marlina, Anggota KWT Pelangi Kopi, Wawancara, Giri Mulyo, 4 Mei 2019.

Juli, Ketua BPD Desa Giri Mulyo, Wawancara, Giri Mulyo, 1 Mei 2019.

Surtini, Petani Kopi (berstatus janda), Wawancara, Giri Mulyo, 4 Mei 2019.

Suwarni, Anggota KWT Pelangi Kopi (berstatus janda), Wawancara, Giri Mulyo, 1 Mei 2019. 